\title{
DÜBLIN
}

Technological University Dublin

ARROW@TU Dublin

Articles

School of Food Science and Environmental

Health

2013-1

\section{Ultrasound for Improved Crystallisation in Food Processing}

\author{
N. Misra \\ Technological University Dublin, misra.nrusimhanath@tudublin.ie \\ Navneet Deora \\ Indian Institute of Technology - Kharagpur \\ Brijesh Tiwari \\ Manchester Metropolitan University
}

See next page for additional authors

Follow this and additional works at: https://arrow.tudublin.ie/schfsehart

Part of the Chemical Engineering Commons, Condensed Matter Physics Commons, and the Food Science Commons

\section{Recommended Citation}

Deora, NS, Misra, NN, Deswal, A, Mishra, HN, Cullen, PJ \& Tiwari BK (2013) Ultrasound for Improved Crystallisation in Food Processing, Food Engineering Reviews, 5(1):36-44. DOI: 10.1007/ s12393-012-9061-0

This Article is brought to you for free and open access by the School of Food Science and Environmental Health at ARROW@TU Dublin. It has been accepted for inclusion in Articles by an authorized administrator of ARROW@TU Dublin. For more information, please contact arrow.admin@tudublin.ie, aisling.coyne@tudublin.ie, gerard.connolly@tudublin.ie.

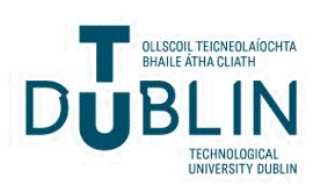


Authors

N. Misra, Navneet Deora, Brijesh Tiwari, and Patrick Cullen

This article is available at ARROW@TU Dublin: https://arrow.tudublin.ie/schfsehart/106 


\title{
Ultrasound for Improved Crystallisation in Food Processing
}

\author{
N. S. Deora $\cdot$ N. N. Misra $\cdot$ A. Deswal $\cdot$ \\ H. N. Mishra • P. J. Cullen • B. K. Tiwari
}

\begin{abstract}
Within the food industry, controlling crystallisation is a key factor governing food structure, texture and consumer appeal, with some foods requiring the promotion of crystallisation in a controlled manner (e.g. chocolate) and others a check (e.g. honey). Sonocrystallisation is the application of ultrasound energy to control the nucleation of a crystallisation process. The use of power ultrasound provides a useful approach to producing crystals with desired properties. Sonocrystallisation facilitates process control by modulating crystal size distribution and morphology. This paper details the governing mechanisms of sonocrystallisation. Proven and potential applications of the process in foods are reviewed including chocolate, honey, fats and frozen foods. Challenges of process adoption such as scale-up are discussed.
\end{abstract}

Keywords Sonocrystallisation · Ultrasound · Honey · Sugar $\cdot$ Crystal

\section{Introduction}

Crystallisation is the formation of highly organised solid particles within a homogeneous phase. Crystals can be

N. S. Deora · A. Deswal · H. N. Mishra

Agricultural and Food Engineering Department, Indian Institute of Technology, Kharagpur 721302, India

N. N. Misra · P. J. Cullen

School of Food Science and Environmental Health, Dublin Institute of Technology, Dublin 1, Ireland

B. K. Tiwari $(\bowtie)$

Manchester Food Research Centre, Manchester Metropolitan University, Manchester M14 6HR, UK

e-mail: b.tiwari@mmu.ac.uk grown from the liquid phase, either within a solution, melt or from the vapour phase. Any liquid solution which is saturated with a solute can be macroscopically considered to be in a thermodynamic equilibrium. However, when the state of the system shifts to non-equilibrium, where the concentration of the solute in the solution exceeds its saturated (or equilibrium) concentration, crystallisation may occur. A system under this state is termed "supersaturated". The degree of supersaturation which depends on the characteristics of the system is the critical driving force for crystal formation and growth. The most common method of creating supersaturated solutions includes: cooling, solvent evaporation, chemical reaction, $\mathrm{pH}$ modification, and alteration in solvent composition. For engineering structured food products involving crystallisation, temperature change and solvent evaporation approaches are typical. Crystallisation from solution involves two distinct steps, nucleation and crystal growth. The former is the birth of new crystals and is partly a probability driven process with the number of nuclei formed governed by a statistical distribution [76]. Crystal growth involves diffusion from bulk of the solution to crystal surface and reaction onto the crystal surface. The overall growth rate $(G)$ is the rate of change of the crystal size $(L)$ with time $(t)$ and can be expressed as:

$G=\frac{\mathrm{d} L}{\mathrm{~d} t}=k_{g} \Delta c^{g}$

where $k_{G}$ is the overall growth rate constant, $\Delta c$ is the supersaturation, and $g$ is the order of growth rate [70]. The properties of the crystals obtained depend on these two steps and their relationship to each other. Qualitatively, when the rate of nucleation is high relative to the growth rate, crystals formed are small and numerous [78]. A detailed insight into the thermodynamics and fundamental 
aspects of crystallization can be obtained from many references [20, 47, 60].

The morphology, shape, and habit of a crystal are generally used to describe a crystal. Morphology indicates a specific characteristic, material and structure-dependent shape for a known crystallizing compound and is described by a combination of miller indices (a form of notation system in crystallography for planes and directions) of each face and unit cell information [2]. Crystal "habit" may be described either with the relative lengths of major axes of the crystal [62] or by the relative rates of its growth in different directions [50]. Habit is also defined by the arrangement of planar faces described by miller indices. Key concepts in crystallisation are summarised in Fig. 1.

Crystallisation influences product quality for food processes including the freeze-concentration of fruit juices, freezing of ice-cream and other foods, freeze-drying, production of edible salt, granulated sugar and chocolates. Obtaining a desired uniform crystal size distribution is a challenge due to the inherently variable nucleation and crystal growth phases. Therefore, a method to control the nucleation phenomena and turn its stochastic behaviour into a repeatable and predictable manner would be valuable for the food industry [31]. The application of ultrasound energy for controlling crystallisation is referred to as sonocrystallisation. Sonocrystallisation offers potential benefits to decrease variability under these situations. The main mechanism of action in power ultrasound is cavitation, a phenomenon that can be either stable or transient. Stable cavitation is associated with small bubbles dissolved in a liquid, while transient cavitation occurs when the bubble size changes quickly and collapses, and as a result locally produces very high pressure $(100 \mathrm{MPa})$ and high temperature $(5,000 \mathrm{~K})[19,64,72]$. The concept of sonocrystallisation emerged around 80 years ago when upon exposing supercooled melts or supersaturated solutions of various substances to ultrasound, the nucleation and/or the growth of crystals was found to be remarkably influenced [3]. However, many of the advancements to date have taken place only in the last decade. Within an ultrasonic field, nucleation is initiated at higher temperatures or in shorter times resulting in more uniform and smaller crystals [44]. Sonocrystallisation offers an advantage over the conventional approaches in the following ways $[30,33,41$, 49]:

1. Better product and process consistency

2. Improved crystal purity

3. Ameliorated secondary physical properties (flowability, packing density, etc.) of the product

4. Shorter crystallisation cycle times and less frequent rework

Sonocrystallisation is an under-researched area of food technology with good potential for improving product quality and process efficiency. This review summarises the various studies to this point regarding sonocrystallisation in food systems, as evidenced from scientific literature and patents, in addition to providing a brief discussion on fundamentals of sonocrystallisation.

\section{Mechanism of Sonocrystallisation}

As ultrasound travels through a liquid medium, it induces cavitation if the amplitude is sufficiently high. Cavitation is caused by the rapid formation and collapse of microscopic bubbles in a liquid and it leads to transmission of ultrasonic energy. Stable cavities are relatively long-lived gas bubbles and exist for many compression and rarefaction cycles [18]. They are produced at low ultrasound intensities and usually oscillate for a number of cycles often nonlinearly about an equilibrium size without collapsing. Transient cavitation occurs when a cavity experiencing vibration increases in size progressively over a succession of compression and rarefaction cycles, until it collapses violently. Most of the effects of power ultrasound (hereafter referred to as ultrasound only) in sonochemistry have been attributed to transient cavitation [40]. The possible physical mechanisms by which ultrasound influences crystallization, such as localised generation of high pressures, agitation,

Fig. 1 Key concepts in crystallisation

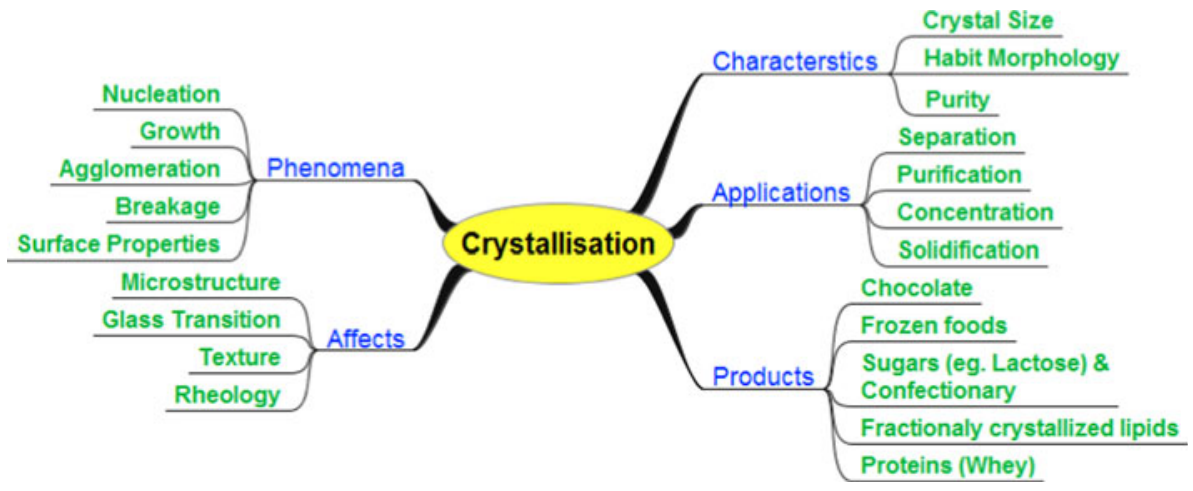


supercooling at the bubble surface, increased melting point of the solute and heterogeneous nucleation were reviewed by Hem, as far back as 1967 [22]. Acoustic cavitation and acoustic streaming are the two major phenomena influencing crystallisation. Acoustic streaming can be described as a steady fluid motion created under the influence of high amplitude acoustic waves, when they propagate through a dissipative fluid medium [63]. Cavitation appears to be particularly effective as a means of inducing nucleation and there is evidence of dramatic improvements in reproducibility obtained through such sononucleation [41]. In addition, acoustic-induced nucleation is a well-defined initial point for the crystallisation process which permits better modulation of crystal growth. Ultrasound induces primary nucleation in nominally particle-free solutions at much lower supersaturation levels compared to conventional mechanical agitation-based crystallisation [66, 67]. Consequently, sononucleation may eliminate the need for crystal seeding.

Luque de Castro and Priego-Capote [41] reviewed the process of sonocrystallisation, wherein they provide a summary of the underlying mechanisms and influence of process variables. One of the postulates is that beside the highly spatially resolved regions of extreme excitation, temperature and pressure created by bubble collapse and concurrent extreme pressures experienced during bubble collapse may reduce the crystallisation temperature with the rapid cooling that accompanies bubble collapse increasing supersaturation
[23]. Ruecroft et al. [67] postulated that the local cooling rates, especially during the rapid growth of cavitation bubbles (calculated at $10^{7}-10^{10} \mathrm{~K} / \mathrm{s}$ ) play a significant part in increasing supersaturation. It is worth noting that even a small change in supersaturation may produce a significant change in the nucleation rate owing to its inherent dependency on supersaturation at a high order. This group has also pointed towards the possible role of high-pressure pulses due to cavitation in the reduction of crystallisation temperature. Recently, Nalajala and Moholkar [54] revealed that shock waves originating from ultrasound increase the nucleation rate and that microturbulence governs the growth of the nuclei. However, the effect of shock waves has been reported to be more pronounced than microturbulence (or microconvection). They also found that nucleation rate shows an order of magnitude rise with sonication, while growth rate (and hence the dominant crystal size) reduces with sonication as compared to a mechanically agitated system used for crystallisation. Observations have pointed towards bubbles as a cause for melting due to their random motion [15]. Such random motion of the cavitation bubble is also associated with breakdown of ice dendrites as they form (shown in Fig. 2).

The zone between the solubility curve and the metastable limit curve (unstable boundary) is known as metastable zone width (MZW) [53]. It provides useful information for developing a controlled crystallisation process. With ultrasonication, the MZW can also be narrowed (Fig. 3). More

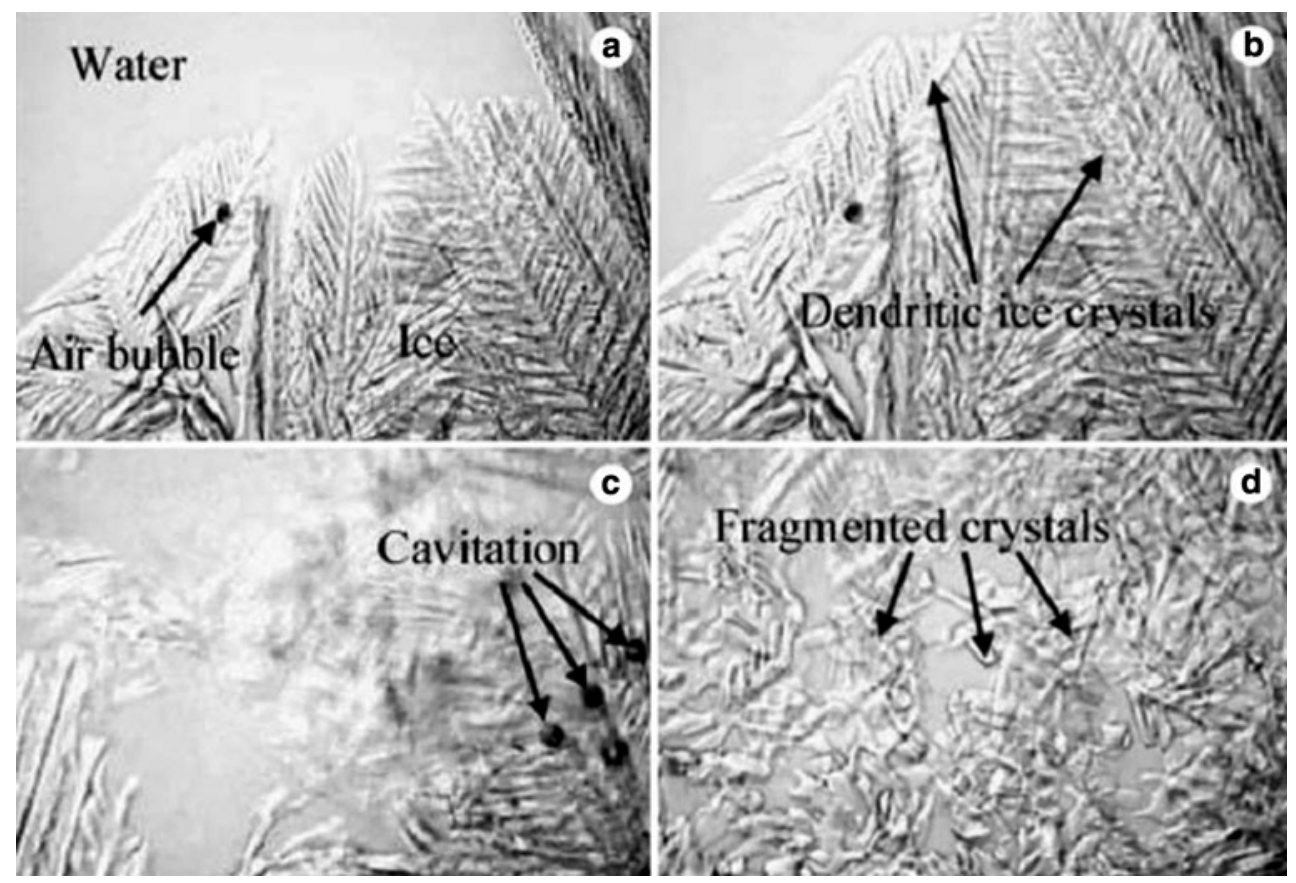

Fig. 2 Secondary nucleation of ice in a $15 \%$ (w/w) sucrose solution-(a) ice dendrite formed when frozen without ultrasound; (b) ice dendrite growth while freezing without ultrasound; (c) fragmentation of ice dendrites after $2 \mathrm{~s}$ of ultrasonication; and (d) fragments of crystals remaining after $4 \mathrm{~s}$ of ultrasonication. Adapted from Chow et al. [15] 


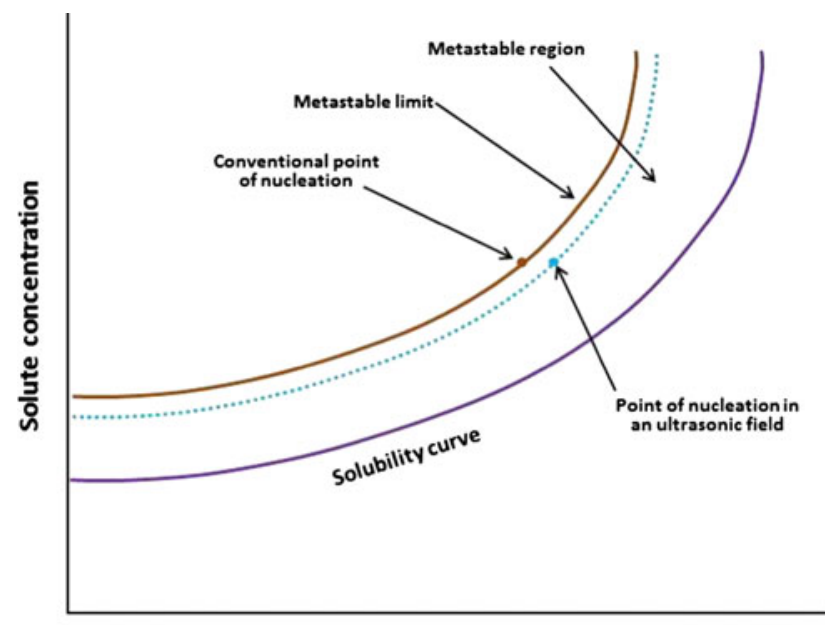

Temperature

Fig. 3 Schematic representation of reduction in the metastable zone using ultrasound

precisely, sonication decreases the apparent order of the primary nucleation rate and increases the rate of appearance of the solid. Seemingly, ultrasonication alters the nucleation mechanism. This has been justified based on the strong reduction in the apparent order of nucleation. In order to establish a relationship between cavitation and nucleation, several theories have been proposed but the contribution of ultrasound to crystallisation is still unclear [83].

A substance capable of forming more than one different crystal is said to exhibit polymorphism, and the different forms are called polymorphs. The shape or morphology of the crystals is paramount to industrial operations (Table 1). In general, it is observed that the supersaturation limit decreases with ultrasonic waves and crystal morphology is modified. Also, the average crystal size decreases in the presence of ultrasonic power [70]. Studies by Li et al. [36] suggest that ultrasound produces a thin film surface layer on the crystal in which the crystallising molecules can better align themselves for incorporation in the unit cell.

To summarise, application of ultrasound to crystallisation results in $[55,73]$ :

1. Nucleation at the lowest level of supersaturation where the crystallisation overcomes the tendency of the compound to re-dissolve in the solution

2. Narrowing of the metastable zone width
3. Narrow particle size distribution

4. Decrease in the level of undercooling necessary to achieve crystallisation (hence avoiding crash crystallisation)

5. Increased repeatability and predictability of crystallisation

6. Polymorph control

It should also be noted that when ultrasound is used to enhance crystallization of any kind, there is an additional benefit in that it helps to prevent encrustation of crystals on the cooling elements, which ensures efficient heat transfer throughout the cooling process [12, 84].

In the past, systems used have relied on high power ultrasonic probes to produce crystals. Use of high intensity probes causes intense cavitation and free radical generation. Further, Sayan et al. [70] reported abrasive effects at higher input powers. Despite the favourable effects of ultrasonication on crystal structure, the aforementioned effects may lead to off-flavour in fats and lipids. However, by keeping the cooling regime constant, it has been found that the structure of the crystallised product can be varied from a material looking similar to cottage cheese through to a fine cream by varying the ultrasonic intensity [59]. The crystallisation process can be controlled by means of the amplitude and frequency of the ultrasonic wave along with the exposure time, thus controlling crystal size distribution as well the point at which crystallisation occurs [61]. An increase in the power dissipation level or increase in the duty cycle means that the number of cavitational events or bubbles generated in the reactor increases. Increasing bubble population may act as templates for new nuclei, increasing the probability of nucleation. High speed images of bubble clouds obtained by Chow et al. [14] from an ultrasonic horn $(27 \mathrm{kHz})$ confirmed the hypothesis of a possible increase in the number of bubbles with an increase in the ultrasonic output. However, an increase in power levels in an attempt to increase the cavitation sites is impractical due to the accompanying global rise in temperature. Accordingly, the importance of temperature control of the process vessel contents during high power ultrasonication is important [34]. Due to the lack of appropriate sonoreactors for crystallisation, only a few limited applications to industrial chemical processing currently exist and on a relatively small scale [24, 45].

Table 1 Characters associated with crystal habits of industrial importance

\begin{tabular}{ll}
\hline Crystal habit/shape & Associated character/behaviour \\
\hline Long, needle-like & Easily broken during centrifugation and drying \\
Flat, plate-like & Difficult to wash during filtration or centrifugation and results in relatively low filtration rates \\
Complex or twinned crystals & More easily broken in transport than compact crystal habits \\
Rounded or spherical crystals & Tend to give considerably less difficulty with caking than do cubical or other compact shapes \\
\hline
\end{tabular}




\section{Sugar Crystallisation}

Sonocrystallisation has been reported to improve the crystallisation of organic compounds of low to medium molecular weight pharmaceuticals [67]. For the food industries, an interesting application of sonocrystallisation is the control of sugar crystallite size. This application is of particular interest since the texture of food products will be affected by the size of undissolved sugar crystals [46]. Ruecroft et al. [67] studied the effect of ultrasonication on the metastable zone width reduction for a range of sugar solutions cooled from 50 to $20^{\circ} \mathrm{C}$. They observed a significant reduction in zone width in all cases, except D-lactose.

Studies by Bund and Pandit [8] have revealed that sonication of a lactose solution (with $85 \% \mathrm{v} / \mathrm{v}$ ethanol as an anti-solvent) in an ultrasonic bath (operating at $22 \mathrm{kHz}$ ) leads to early crystallisation ( $92 \%$ recovery) of lactose as compared to $15 \%$ recovery for control mechanically stirred samples. They also reported an improvement in the size and shape characteristics of the lactose crystals. This rapid crystallisation has been attributed to the enhanced mixing of the anti-solvent into the solution and possibly either by solvent depletion in the zone of a cavitation bubble or by cavitation bubbles themselves acting as crystal nucleation sites. In contrast to the mentioned studies, Hu et al. [26] reported insignificant effects on white sugar quality during their studies on ultrasound-aided scale control in evaporative systems. Further studies in this area using a range of consistent ultrasound parameters are likely to help in drawing clear insights.
Honey is a supersaturated solution of glucose and it has a tendency to crystallize spontaneously at room temperature in the form of glucose monohydrate. Heat treatment has been employed traditionally to dissolve D-glucose monohydrate crystals in honey and delay crystallisation. However, this approach negatively affects the fine-spun flavour of honey. The beneficial application of power ultrasound in honey has been reported by many researchers [29, 39, 75]. The application of ultrasound has been shown to eliminate existing crystals and also retard the crystallisation process resulting in a cost-effective technology $[38,39]$. Analysis of the crystallisation process suggests that sonicated honey samples remained in liquid state for longer periods than heat-treated honey [75]. In addition, no significant effects on honey quality parameters, such as moisture content, electrical conductivity or $\mathrm{pH}$, were observed. Studies have shown that, in general, ultrasound treatment (with a $24 \mathrm{kHz}$ probe, in batch treatment) leads to faster dissolution of crystals than thermal treatment [5]. Thrasyvoulou et al. [75] liquefied crystallized honey samples by ultrasonic waves at $23 \mathrm{kHz}$ and by heating at $60{ }^{\circ} \mathrm{C}$ for $30 \mathrm{~min}$. They reported that the average increase in Hydroxy Methyl Furfural (HMF) content was significantly lower $(86 \%)$ in samples liquefied by sonication compared to samples liquefied by heating (129\%).

Recently, Kabbani et al. [28] crystallized rosemary honey samples treated in an ultrasound bath, filled with distilled water, at a frequency of $40 \mathrm{kHz}$ in a temperature range of $40-60{ }^{\circ} \mathrm{C}$. When honey was exposed to ultrasound waves or heated, the sugar crystals redissolve to a liquid state. This group reported that ultrasound-treated honey
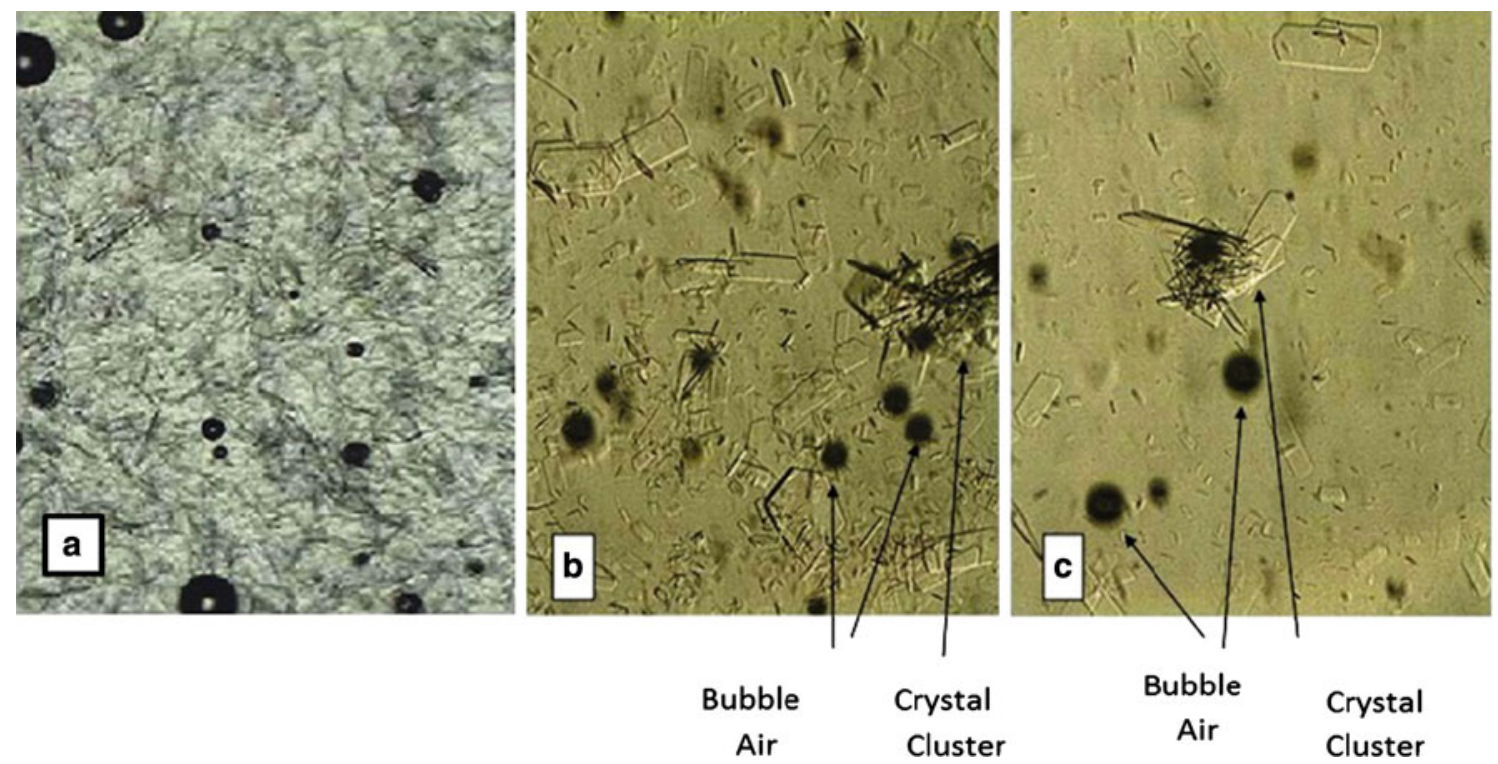

Crystal

Cluster

Fig. 4 Microscopic images of treated honey (a) Control sample. Before being treated, honey appears as network of needle-shaped crystals. Dark circles are air bubbles. b $40{ }^{\circ} \mathrm{C}$ heat-treated samples after 20 min of thermal treatment; $\mathbf{c} 40{ }^{\circ} \mathrm{C}+$ US-treated samples after 20 min of treatment. Adapted from Kabbani et al. [27] 
presents a clearer appearance than heat treatment alone (Fig. 4). Another important finding from this study was that honey can be liquefied by ultrasound waves without the need to increase the temperature to $50{ }^{\circ} \mathrm{C}$ or higher.

\section{Crystallisation of Ice and Freezing of Foods}

Freezing and crystallization are linked in that both processes involve initial nucleation followed by crystallization [69]. Research on sonocrystallisation links cavitation and the nucleation of ice crystals. Cavitation bubbles arising from sonication benefit the freezing process by reducing the resistance to both heat and mass transport at the ice/ liquid interface, thereby increasing the freezing rate $[4,13]$. McCausland and Cains [48] have reported enhancement in nucleation, reduced crystal induction time, more uniform crystal growth and reproducibility using high intensity low frequency ultrasound. By applying ultrasound at $\sim 70 \mathrm{kHz}$, they observed that cavitation bubbles $(\sim 30$ micron diameter) formed between the growing boundaries of the ice crystals. The random motion of the cavitation bubble is also suspected to break down any ice dendrites as they form [15]. As far back as 1964, Chalmers [9] observed the primary nucleation of ice to occur at higher temperatures in an ultrasonic field-consistent with the expansion of water upon freezing. Studies of both primary and secondary nucleation of ice in sucrose solutions have shown that both can be achieved at higher nucleation temperatures in the presence of ultrasound. Increasing the ultrasound power level and pulse duration raises the nucleation temperature $[13,14]$.

To obtain a greater insight into the sonocrystallisation mechanism of ice, Chow et al. [15] employed a customised system for sonication and an optical microscope to capture the dynamic images. They reported three distinct phenomena occurring in sonocrystallisation:

- Formation of cavitation bubbles at grain boundaries between ice crystals.

- Progressive melting of ice by cavitation bubbles which appear to eat their way into the ice phase.

- Fragmentation of dendritic ice structures, thereby increasing the probability of secondary nucleation.

Olmo et al. [58] employed a novel droplet nucleation analyser (DNA) to study the influence of ultrasonic waves on the freezing of distilled water. They observed no significant influence on the freezing parameters of the droplets when ultrasound is applied at non-cavitational intensities $\left(0.15 \mathrm{~W} / \mathrm{cm}^{2}\right)$. The DNA is particularly useful to study the nucleation process as a stochastic model. Recently, Saclier et al. [68] froze $10 \% \mathrm{w} / \mathrm{w}$ mannitol aqueous solution samples to establish correlations between the final frozen product ice crystal characteristics and ultrasound-assisted freezing operating conditions. Their work revealed that an increase in supercooling and acoustic power resulted in decreased mean size and increased mean circularity of ice crystals as observed with optical microscopy.

Similar to any dense and incompressible material, ice crystals too fracture when subjected to alternating acoustic stress, leading to products of smaller crystal size distribution. A small crystal size is highly desirable in many freezing processes, including ice-cream manufacture and freeze-drying [84]. In another context, acoustically aided frozen potatoes have been found to retain better microstructure. This has been attributed to the high freezing rates obtained under high ultrasonic levels and thus the domination of small intracellular ice crystals [71]. It has also been shown that ultrasound is beneficial to ice-cream freezing by shortening the process time [52]. Under the influence of power ultrasound, a more rapid and even seeding occurs which leads to shorter times between the initiation of crystallisation and the complete formation of ice, ultimately reducing cellular damage [71]. Extensive research on the use of power ultrasound as a novel technology to promote the nucleation of ice has been carried out by Sun and co-workers [16, 35, 71, 84]. However, there are several issues pertaining to the development of ultrasonic freezers which are yet to be addressed before industrial scale processing can be realised.

The fact that flow streams cannot be generated in solid foods as they are produced in fluid samples points towards the need for study of effect of ultrasound on the nucleation of water in solid samples. In this regard, Kiani et al. [32] have demonstrated the ability of ultrasound to trigger nucleation in agar gel, as a solid model food. Recently, the effect of irradiation temperature, irradiation duration and ultrasound intensity on the dynamic nucleation of ice in agar gel samples was reported by Kiani et al. [31]. This group has also emphasised upon the need for optimisation of process parameters.

\section{Crystallisation of Fats}

Crystallisation of fats is of considerable interest in chocolate manufacture. For semi-solid fat products such as chocolates or cocoa butter, the rheological properties of fats are the result of a combined effect of the SFC (solid fat content) and the three-dimensional colloidal fat crystal network micro-structure, including the shape, size, spatial distribution pattern of the crystals $[17,21,37,42,56,57$, $79,80,82]$. Cocoa butter can crystallise in a number of polymorphic forms depending on the triglyceride composition [1]. Cocoa butter has six polymorphic crystal forms (I-VI), the principals being $\alpha, \beta$ and $\beta^{\prime}$ (Table 2). The 
Table 2 Melting point of the polymorphic forms of cocoa butter

\begin{tabular}{lll}
\hline Polymorphic forms of cocoa butter & Melting point $\left({ }^{\circ} \mathrm{C}\right)$ \\
\hline Form I & $\beta_{2}^{\prime}$ & $16-18$ \\
Form II & $\alpha$ & $21-22$ \\
Form III & Mixed & 25.5 \\
Form IV & $\beta_{1}$ & $27-29$ \\
Form V & $\beta_{2}$ & $34-35$ \\
Form VI & $\beta_{1}^{\prime}$ & 36
\end{tabular}

Adapted from [74] with modifications

polymorphic forms can be determined by X-ray diffraction. Form $\mathrm{V}$, in general is the most desirable crystal form in well-tempered chocolate, imparting resistance to bloom and good visual sensation [7].

In the traditional tempering sequence, to avoid fat bloom on chocolates, the unstable forms III and IV of cocoa butter are crystallised during the first cooling process after which they transform to stable polymorphs of form $\mathrm{V}$ during the reheating process by a melt-mediated transformation. However, in the case of sonocrystallisation $(20 \mathrm{kHz}$, $100-300 \mathrm{~W}$ for $3 \mathrm{~s}$ ) for tripalmitoylglycerol and cocoa butter, it has been found that the stable form is directly crystallised without the formation and subsequent meltmediation of the unstable forms [25, 77]. This points to the fact that ultrasound irradiation is an efficient tool for controlling polymorphic crystallisation of fats and a reduction in induction times [51]. Also, for a given fat, once the range of crystal structures has been determined, it is possible to select a particular texture by choosing appropriate ultrasound intensity. Baxter et al. [6] patented a method for retarding fat bloom on chocolate and other fat compositions comprising of cocoa butter. The method involves undercooling of the molten fat by at least $3{ }^{\circ} \mathrm{C}$ below the melting point of the $\beta$-polymorph crystal and exposure to an effective amount of ultrasonic energy. Also, the group invented a method for accelerating the polymorphic transformation of edible fat compositions, typically butter fats and fats used in ice-cream, chocolate, margarine and yoghurt. The patent claims that by undercooling the compositions by $4{ }^{\circ} \mathrm{C}$ and optimising the time and frequency of sonication, stable polymorphs can be induced without exceeding the melting point. U.S. Patent 6,630,185 which cites the above two patents is another important invention in relation to sonocrystallisation of fats [3].

Applications of ultrasound in the dairy industry have been reviewed by Villamiel et al. [81]. An ultrasonication study of the fat globules present in dairy systems revealed its potential to provide a unique opportunity to balance the crystallised and uncrystallised fat ingredients. Martini et al. [43] studied the effect of high intensity ultrasound on the crystallisation of fats and found that faster crystallisation can be achieved with smaller crystals. The samples showed increased viscosity after sonication due to fat crystallisation.

The documented effects of ultrasound-induced cavitation on the production of free radicals appear to have restricted the use of sonocrystallisation for systems involving fats and oils, which are susceptible to free radicals $[3,65]$. Therefore, in spite of an improvement in the structure of the crystallised product, reports of off-flavours $[10,11]$ have most likely prevented it from being a viable choice for the crystallisation of edible fats. On the contrary, Patrick et al. [59] reported that sonication at $66 \mathrm{kHz}$ did not cause any off-flavour production due to oxidative changes to palm oil. Their results indicate that the optimum conditions for obtaining small crystals in the shortest time period is just below the cavitation intensity threshold. Various crystal structures depending on the intensity have been observed by this team in sonicated $(65 \mathrm{kHz})$ palm oil.

\section{Conclusions}

Crystallization is a complex process that is difficult to control. Research shows that ultrasound has potential to provide improved control over the crystallisation process and ultimately food product microstructure. Sonocrystallisation enables significant reductions in the processing times and the generation of better quality crystals. Ultrasound-induced cavitation exerts positive effects on nucleation, crystal growth and transport processes across solidliquid boundaries. Extrinsic control parameters such as frequency, amplitude, ultrasonic intensity, treatment time and temperature strongly influence these effects. Despite the nucleation and crystal growth phenomena occurring sequentially in any crystallization process, the difficulty in carrying out fundamental investigations lies in the fact that they are difficult to decouple.

From a food industry perspective, crystallisation of sugars, honey, ice, fats and oils are a few areas that have been explored to date. Although sonocrystallisation is a mature technology within the fields of pharmaceuticals and fine chemicals, its implementation at an industrial scale for foods is still in its infancy and needs further investigation. This also includes the development of continuous, contamination-free sonocrystallisers.

\section{Future Trends}

Ultrasound is an emerging technology with several potential applications in crystallised foods. In spite of the promising published data, in most of the cases, no decisive success in the food industry has been achieved to date. 
Studies to examine the complex mechanisms involved in sonocrystallisation and the parameters governing scale-up need focus. Future research should report standardised sonication process parameters to facilitate comparisons between studies to assess the effects of ultrasound variables on crystallisation behaviour. Numerical modelling such as computational fluid dynamics (CFD) coupled with population balance modelling (PBM) is likely to provide more information and a better understanding of the phenomena involved.

\section{References}

1. Afoakwa EO, Paterson A, Fowler M (2007) Factors influencing rheological and textural qualities in chocolate-a review. Trends Food Sci Technol 18(6):290-298. doi:10.1016/j.tifs.2007.02.002

2. Alatalo H (2010) Supersaturation-controlled crystallization. Lappeenranta University of Technology, Finland

3. Arends BJ, Blindt RA, Janssen J, Patrick M (2001) Crystallisation process using ultrasound. USA patent

4. Ashokkumar M, Grieser F (1999) Ultrasound assisted chemical processes. Rev Chem Eng 15(1):41-83. doi:10.1515/REVCE. 1999.15.1.41

5. Basmaci I (2010) Effect of ultrasound and high hydrostatic pressure (HHP) on liquefaction and quality parameters of selected honey varieties. Master's thesis, Middle East Technical University

6. Baxter JF, Morris GH, Gaim-Marsoner G (2001) Process for retarding fat bloom in fat-based confectionery masses

7. Beckett ST (2008) The science of chocolate, 2nd edn. Royal Society of Chemistry, Cambridge

8. Bund RK, Pandit AB (2007) Rapid lactose recovery from paneer whey using sonocrystallization: a process optimization. Chem Eng Process 46(9):846-850. doi:10.1016/j.cep.2007.05.015

9. Chalmers B (1964) Principles of solidification. Wiley, New York

10. Chemat F, Grondin I, Costes P, Moutoussamy L, Sing ASC, Smadja J (2004) High power ultrasound effects on lipid oxidation of refined sunflower oil. Ultrason Sonochem 11(5):281-285. doi: 10.1016/j.ultsonch.2003.07.004

11. Chemat F, Grondin I, Shum Cheong Sing A, Smadja J (2004) Deterioration of edible oils during food processing by ultrasound. Ultrason Sonochem 11(1):13-15. doi:10.1016/S1350-4177(03) 00127-5

12. Chemat F, Zill-e-Huma S, Khan MK (2010) Applications of ultrasound in food technology: processing, preservation and extraction. Ultrason Sonochem

13. Chow R, Blindt R, Chivers R, Povey M (2003) The sonocrystallisation of ice in sucrose solutions: primary and secondary nucleation. Ultrasonics 41(8):595-604. doi:10.1016/j.ultras.2003. 08.001

14. Chow R, Blindt R, Chivers R, Povey M (2005) A study on the primary and secondary nucleation of ice by power ultrasound. Ultrasonics 43(4):227-230. doi:10.1016/j.ultras.2004.06.006

15. Chow R, Blindt R, Kamp A, Grocutt P, Chivers R (2004) The microscopic visualisation of the sonocrystallisation of ice using a novel ultrasonic cold stage. Ultrason Sonochem 11(3-4):245250. doi:10.1016/j.ultsonch.2004.01.018

16. Delgado AE, Zheng L, Sun DW (2009) Influence of ultrasound on freezing rate of immersion-frozen apples. Food Bioprocess Technol 2(3):263-270
17. Deman J, Beers A (1987) Fat crystal networks: structure and rheological properties. J Texture Stud 18(4):303-318

18. Ensminger D (1973) Ultrasonics, the low- and high-intensity applications, vol 19, vol 4. Marcel Dekker, Inc., New York. doi: 10.1002/aic.690190442

19. Flynn H (1964) Physics of acoustic cavitation in liquids. In: Mason WP (ed) Physical acoustics, vol 1B. Academic Publisher, New York, pp 57-172

20. Hartel RW (2001) Crystallization in foods. Aspen Publishers, Gaithersburg

21. Heertje I (1993) Microstructural studies in fat research. Food Struct 12:77-94

22. Hem SL (1967) The effect of ultrasonic vibrations on crystallization processes. Ultrasonics 5(4):202-207. doi:10.1016/0041$624 \times(67) 90061-3$

23. Hickling R (1965) Nucleation of freezing by cavity collapse and its relation to cavitation damage. Nature 206(4987):915-917

24. Hielscher (2011) HielscherGú-ultrasound technology http://www. hielscher.com/ultrasonics/i1000_p.htm. Accessed 12 Feb 2011, Hielscher-i1000

25. Higaki K, Ueno S, Koyano T, Sato K (2001) Effects of ultrasonic irradiation on crystallization behavior of tripalmitoylglycerol and cocoa butter. J Am Oil Chem Soc 78(5):513-518. doi:10.1007/ s11746-001-0295-y

26. Hu A, Zheng J, Qiu T (2006) Industrial experiments for the application of ultrasound on scale control in the Chinese sugar industry. Ultrason Sonochem 13(4):329-333. doi:10.1016/j.ultsonch. 2005.05.005

27. Kabbani D, Sepulcre F, Wedekind J (2011) Ultrasound-assisted liquefaction of rosemary honey: influence on rheology and crystal content. J Food Eng 107(2):173-178. doi:10.1016/j.jfoodeng. 2011.06.027

28. Kabbani D, Sepulcre F, Wedekind J (2011b) Ultrasound-assisted liquefaction of rosemary honey: influence on rheology and crystal content. J Food Eng

29. Kaloyereas SA (1955) Preliminary report on the effect of ultrasonic waves on the crystallization of honey. Science 121(3140): 339-340. doi:10.1126/science.121.3140.339

30. Keshava Prakash MN, Ramana KVR (2003) Ultrasound and its application in the food industry. J Food Sci Technol 40(6): 563-570

31. Kiani H, Sun DW, Delgado A, Zhang Z (2012) Investigation of the effect of power ultrasound on the nucleation of water during freezing of agar gel samples in tubing vials. Ultrason Sonochem 19(3):576-581. doi:10.1016/j.ultsonch.2011.10.009

32. Kiani H, Zhang Z, Delgado A, Sun DW (2011) Ultrasound assisted nucleation of some liquid and solid model foods during freezing. Food Res Int

33. Kordylla A, Koch S, Tumakaka F, Schembecker G (2008) Towards an optimized crystallization with ultrasound: effect of solvent properties and ultrasonic process parameters. J Cryst Growth 310(18):4177-4184. doi:10.1016/j.jcrysgro.2008.06.057

34. Krishna Sandilya D, Kannan A (2010) Effect of ultrasound on the solubility limit of a sparingly soluble solid. Ultrason Sonochem 17(2):427-434. doi:10.1016/j.ultsonch.2009.10.005

35. Li B, Sun DW (2002) Effect of power ultrasound on freezing rate during immersion freezing of potatoes. J Food Eng 55(3):277-282

36. Li H, Li H, Guo Z, Liu Y (2006) The application of power ultrasound to reaction crystallization. Ultrason Sonochem 13(4):359-363. doi:10.1016/j.ultsonch.2006.01.002

37. Liang B, Hartel RW (2004) Effects of milk powders in milk chocolate. J Dairy Sci 87(1):20. doi:10.3168/jds.S0022-0302 (04)73137-9

38. Liebl DE (1977) Method of preserving honey. US Patent $4,050,952$ 
39. Liebl DE (1978) Ultrasound and granulation in honey. Am Bee J (USA) 118(2):107

40. Luche JL, Bianchi C (1998) Synthetic organic sonochemistry. Plenum Press, New York

41. Luque de Castro MD, Priego-Capote F (2007) Ultrasound-assisted crystallization (sonocrystallization). Ultrason Sonochem 14(6): 717-724. doi:10.1016/j.ultsonch.2006.12.004

42. Marangoni AG, Rousseau D (1996) Is plastic fat rheology governed by the fractal nature of the fat crystal network? J Am Oil Chem Soc 73(8):991-994. doi:10.1007/BF02523406

43. Martini S, Suzuki AH, Hartel RW (2008) Effect of high intensity ultrasound on crystallization behavior of anhydrous milk fat. J Am Oil Chem Soc 85(7):621-628. doi:10.1007/s11746-008-1247-5

44. Mason TJ (2007) Developments in ultrasound-non-medical. Prog Biophys Mol Biol 93(1-3):166-175. doi:10.1016/j.pbiomolbio. 2006.07.007

45. Mason TJ, Lorimer JP (eds) (2002) Applied sonochemistry: the uses of power ultrasound in chemistry and processing. Wiley, Weinheim

46. Mason TJ, Paniwnyk L, Lorimer JP (1996) The uses of ultrasound in food technology. Ultrason Sonochem 3(3):S253-S260. doi:10.1016/s1350-4177(96)00034-x

47. McCabe WL, Smith JC, Harriott P (2004) Crystallization. In: Unit operations of chemical engineering, 7 edn. McGraw-Hill Book Company, New York

48. McCausland L, Cains P (2003) Sonocrystallization using ultrasound to improve crystallization products and processes. Chem Ind 5:15-17

49. McCausland LJ, Cains PW (2004) Power ultrasound: a means to promote and control crystallization in biotechnology. Biotechnol Genet Eng Rev 21:3-10

50. Mersmann A (2001) Crystallization technology handbook, 2nd edn. Marcel Dekker Inc., New York

51. Misra NN (2010) Applications of external fields in food and bioprocessing. Masters thesis, CFTRI, University of Mysore, Mysore

52. Mortazavi A, Tabatabaie F (2008) Study of ice cream freezing process after treatment with ultrasound. World Appl Sci J 4(2):188-190

53. Myerson AS (2002) Handbook of industrial crystallization, 2nd edn. Butterworth-Heinemann, Woburn

54. Nalajala VS, Moholkar VS (2011) Investigations in the physical mechanism of sonocrystallization. Ultrason Sonochem 18(1): 345-355. doi:10.1016/j.ultsonch.2010.06.016

55. Narducci O, Jones AG, Kougoulos E (2011) Continuous crystallization of adipic acid with ultrasound. Chem Eng Sci 66(6):1069-1076. doi:10.1016/j.ces.2010.12.008

56. Narine SS, Marangoni AG (1999) Relating structure of fat crystal networks to mechanical properties: a review. Food Res Int 32(4):227-248

57. Nederveen C (1963) Dynamic mechanical behavior of suspensions of fat particles in oil. J Colloid Sci 18(3):276-291

58. Olmo A, Baena R, Risco R (2008) Use of a droplet nucleation analyzer in the study of water freezing kinetics under the influence of ultrasound waves. Int J Refrig 31(2):262-269. doi: 10.1016/j.ijrefrig.2007.05.012

59. Patrick M, Blindt R, Janssen J (2004) The effect of ultrasonic intensity on the crystal structure of palm oil. Ultrason Sonochem 11(3-4):251-255. doi:10.1016/j.ultsonch.2004.01.017

60. Perry RH, Green DW (2007) Perry's chemical engineers' handbook, 8th edn. McGraw-Hill Professional, New York

61. Povey MJW, Mason TJ (1998) Ultrasound in food processing. Blackie Academic and Professional, London

62. Randolph AD, Larson MA (1988) Theory of particulate processes: analysis and techniques of continuous crystallization, 2nd edn. Academic Press Inc., San Diego
63. Rayleigh L (1884) On the circulation of air observed in Kundt's tubes, and on some allied acoustical problems. Philos Trans R Soc Lond 175:1-21. doi:10.1098/rstl.1884.0002

64. Rayleigh L (1917) On the pressure developed in a liquid during the collapse of a spherical cavity. Philos Mag Ser 6 34(200): 94-98. doi:10.1080/14786440808635681

65. Riener J, Noci F, Cronin DA, Morgan DJ, Lyng JG (2009) Characterisation of volatile compounds generated in milk by high intensity ultrasound. Int Dairy J 19(4):269-272. doi:10.1016/ j.idairyj.2008.10.017

66. Ruecroft G (2007) Power ultrasound and particle engineering. Crystals for drug delivery and formulation. Chim Oggi 25(3):12-14

67. Ruecroft G, Hipkiss D, Ly T, Maxted N, Cains PW (2005) Sonocrystallization: the use of ultrasound for improved industrial crystallization. Org Process Res Dev 9(6):923-932. doi: 10.1021/op050109x

68. Saclier M, Peczalski R, Andrieu J (2010) Effect of ultrasonically induced nucleation on ice crystals' size and shape during freezing in vials. Chem Eng Sci 65(10):3064-3071. doi:10.1016/j.ces. 2010.01.035

69. Sanz P, Otero L, De Elvira C, Carrasco J (1997) Freezing processes in high-pressure domains. Int J Refrig 20(5):301-307

70. Sayan P, Sargut ST, Kiran B (2011) Effect of ultrasonic irradiation on crystallization kinetics of potassium dihydrogen phosphate. Ultrason Sonochem 18(3):795-800. doi:10.1016/j.ultsonch.2010. 11.003

71. Sun D-W, Li B (2003) Microstructural change of potato tissues frozen by ultrasound-assisted immersion freezing. J Food Eng 57(4):337-345. doi:10.1016/s0260-8774(02)00354-0

72. Suslick KS, Nyborg WL (1990) Ultrasound: its chemical, physical and biological effects. J Acoust Soc Am 87(2):919-920. doi: $10.1121 / 1.398864$

73. Syrris (2011) Atlas Sonolab systems. http://www.syrris.com/ applications/. Accessed 26 Feb 2011

74. Talbot G (2008) Chocolate temper. In: Beckett ST (ed) Industrial chocolate manufacture and use, 4th edn. Blackwell Science, Oxford, pp 218-230

75. Thrasyvoulou A, Manikis J, Tselios D (1994) Liquefying crystallized honey with ultrasonic waves. Apidologie (France) 25(3):297-302. doi:10.1051/apido:19940304

76. Toschev NS (1973) Homogeneous nucleation. In: Hartman P (ed) Crystal growth: an introduction, 1st edn. North-Holland Publishing Company, Netherlands

77. Ueno S, Ristic RI, Higaki K, Sato K (2003) In situ studies of ultrasound-stimulated fat crystallization using synchrotron radiation. J Phys Chem B 107(21):4927-4935. doi:10.1021/jp027840f

78. Ulrich J (2000) Crystallization. In: Kirk-Othmer encyclopedia of chemical technology. Wiley, New York. doi:10.1002/0471 238961.0318251918152119.a01.pub2

79. Van den Tempel M (1961) Mechanical properties of plasticdisperse systems at very small deformations. J Colloid Sci 16(3):284-296

80. Van den Tempel M (1979) Rheology of concentrated suspensions. J Colloid Interface Sci 71(1):18-20

81. Villamiel M, Van Hamersveld EH, De Jong P (1999) Effect of ultrasound processing on the quality of dairy products. Milchwissenschaft 54(2):69-73

82. Vreeker R, Hoekstra L, Den Boer D, Agterof W (1992) Fractal aggregation of whey proteins. Food Hydrocoll 6(5):423-435. doi: 10.1016/S0268-005X(09)80028-3

83. Wohlgemuth K, Ruether F, Schembecker G (2010) Sonocrystallization and crystallization with gassing of adipic acid. Chem Eng Sci 65(2):1016-1027. doi:10.1016/j.ces.2009.09.055

84. Zheng L, Sun D-W (2006) Innovative applications of power ultrasound during food freezing processes-a review. Trends Food Sci Technol 17(1):16-23. doi:10.1016/j.tifs.2005.08.010 